\title{
A parceria entre Minas Gerais e o Banco Mundial: uma análise do uso de condicionantes como instrumento de influência
}

\author{
The partnership between Minas Gerais and the \\ World Bank: an analysis of the use of conditionality \\ as an influence tool
}

DOI: $10.21530 /$ ci.v12n1.2017.507

Diogo de Paula Oliveira ${ }^{1}$ Pascoal Teófilo Carvalho Gonçalves²

\section{Resumo}

Este trabalho se propõe a verificar a capacidade do Banco Mundial em influenciar a estratégia de desenvolvimento do governo de Minas Gerais, entre 2006 e 2012, por meio da imposição de condicionantes nos empréstimos realizados pelo primeiro ao segundo. Para cumprir tal objetivo, é apresentada a trajetória histórica do banco, visando compreender suas estratégias de atuação e seus instrumentos de influência. Posteriormente, foram abordados conceitos centrais para a atuação do Banco Mundial, como as condicionantes, a ownership e a seletividade. Por fim, realizou-se uma análise comparada dos documentos de empréstimos e dos planos estratégicos do Estado. A conclusão da pesquisa aponta no sentido de o Banco não exercer influência determinante na estratégia de desenvolvimento de Minas Gerais mediante o uso de condicionantes. O resultado está em linha com a nova forma de atuação declarada pelo BIRD, que mediante a verificação do nível de ownership como critério para o recebimento de empréstimos, não mais utiliza as condicionantes como instrumento de coerção. É plausível que o Banco Mundial exerça uma influência prévia na definição da estratégia de desenvolvimento estadual, uma vez que o Estado pode definir uma estratégia de desenvolvimento compatível à do BIRD para acessar suas linhas de financiamento.

Palavras-chave: Estratégia de Desenvolvimento; Cooperação Internacional para o Desenvolvimento; Banco Mundial; Minas Gerais; Condicionantes.

1 Especialista em Políticas Públicas e Gestão Governamental pelo governo do estado de Minas Gerais E-mail: diogoo_28@hotmail.com

2 Professor/pesquisador do departamento de Relações Internacionais da UFPB. E-mail: pascoalgoncalves@outlook.com

Artigo submetido em 19/08/2016 e aprovado em 16/03/2017. 


\section{Abstract}

This paper aims to examine the capacity of the World Bank to influence the development strategies of the government of Minas Gerais between 2006 and 2012 through the imposition of conditionality attached to its loans. To reach this objective, the trajectory of the bank is presented to understand its operational strategies and influence instruments. Next, important concepts such as conditionality, ownership and selectivity are analyzed. Last, a comparative analysis of the documentation for the loans granted, and the States' strategic plans is made. The conclusion of this research shows that the World Bank does not seem to exert a strong influence on Minas Gerais' development strategy through the use of conditionality. This result is in line with what the IBRD declares to be its new loan policy. By analyzing the ownership level of a country as a criterion for receiving loans, the World Bank does not use conditionality as a coercive instrument. It is plausible that the Bank does exert its influence in a previous stage, when the government is deciding its development strategy, since it might be an interesting option for governments to choose strategies compatible with those defended by the Bank, as a way to access its funds.

Keywords: Development strategies; International Cooperation for Development; World Bank; Minas Gerais; Conditionality.

\section{Introdução}

O Banco Mundial foi criado em 1944 como Banco Internacional de Reconstrução e Desenvolvimento (BIRD), tendo em vista auxiliar na reconstrução da Europa no Pós-Guerra. Somente a partir dos anos de 1960, todavia, o banco passa a prestar auxílio para o desenvolvimento dos países do chamado Terceiro Mundo. Em um primeiro momento, o auxílio era direcionado a projetos de infraestrutura, mas, posteriormente, o combate à pobreza também passou a ser contemplado. A partir da década de 1980, o BIRD constata que o apoio a projetos isolados não seria suficiente para produzir desenvolvimento, caso a estrutura institucional do país financiado não fosse adequada. Com isso, o banco introduz os empréstimos de ajuste estrutural, voltados para o financiamento de políticas e não apenas de projetos (SANTOS JUNIOR, 2010). É a partir daí que as condicionantes - condições definidas em contrato que devem ser cumpridas para que o BIRD proceda à liberação de recursos - passam a ser utilizadas mais extensivamente.

Todavia, a partir dos anos de 1990 e a utilização de condicionantes atreladas ao Consenso de Washington, o Banco Mundial passa a adotar conceitos como ownership e seletividade em seus programas de empréstimo e ajuda. Nesse sentido, 
o interesse de um determinado país em perseguir certas reformas, independente de incentivos externos, passa a ser visto como essencial: seria mais eficiente emprestar apenas para tais países.

Tendo em vista esse contexto, temos que, desde sua fundação, o Banco Mundial realizou 16 empréstimos ao estado de Minas Gerais, sendo cinco no período entre 2006 e 2012. Desses cinco, quatro foram empréstimos para o financiamento de políticas públicas, chamados de Parcerias para o Desenvolvimento de Minas Gerais, que financiaram parte da reforma de Estado conhecida como Choque de Gestão.

O presente artigo parte da hipótese de que o Banco Mundial, por meio do atrelamento da liberação de recursos ao cumprimento de condicionantes definidas em contrato, consegue influenciar a estratégia de desenvolvimento e, por conseguinte, a elaboração e implementação de políticas públicas nos Estados para os quais realiza empréstimos ${ }^{3}$. De forma mais específica, se buscará entender em que medida as condicionantes impostas em três empréstimos realizados entre 2006 e 2012 influenciaram a política de desenvolvimento de Minas Gerais. Caso a hipótese apresentada seja confirmada, se depreenderá que o BIRD consegue impor condicionantes que são estabelecidas de forma externa aos governos democráticos e, possivelmente, forçam a implementação de políticas que não respondem aos anseios da população. Dessa forma, a parceria com o Banco Mundial poderia ser considerada como um fator de interferência na soberania do estado e de enfraquecimento do processo democrático.

Tendo em vista a corroboração ou refutação de nossa hipótese, nossos objetivos específicos são: definir o modelo de desenvolvimento do Banco Mundial; entender como o Banco Mundial define quais ações serão financiadas e quais condicionantes serão aplicadas em um empréstimo; e verificar se há uma convergência entre os objetivos governamentais e as ações e condicionantes dos empréstimos do banco.

Cabe ressaltar que não trataremos nesse trabalho da relação entre democracia, desenvolvimento e a atuação do Banco Mundial, e, tampouco, entraremos em detalhes quanto ao processo de formulação de políticas públicas. Nosso foco está na verificação da capacidade de influência do BIRD sobre a estratégia de desenvolvimento do Estado de Minas Gerais via condicionantes.

O artigo está estruturado da seguinte forma: na primeira seção, será apresentada a evolução histórica do Banco Mundial, abordando as diferentes fases de atuação

3 No âmbito deste trabalho, entenderemos por formulação de políticas públicas o processo que traduz os propósitos e plataformas eleitorais em programas e ações que produzem resultados ou mudanças no mundo real, conforme Gatti (2011). 
do BIRD a partir da década de 1980. Com isso, busca-se compreender a evolução do conceito de desenvolvimento defendido pelo banco, assim como as estratégias empregadas para alcançá-lo. Na segunda seção, se abordará alguns conceitos importantes que pautam a atuação do BIRD a partir de 2003. Na terceira seção, serão apresentados os empréstimos realizados pelo Banco Mundial ao estado de Minas Gerais a partir de 2006, abordando o contexto de assinatura do empréstimo, seus objetivos e, principalmente, o nível de aderência entre os objetivos do empréstimo e os objetivos previamente declarados pelo governo em seu plano estratégico de longo prazo, o Plano Mineiro de Desenvolvimento Integrado (PMDI). Valemo-nos de revisão bibliográfica sobre o Banco Mundial e de análise documental, referente a empréstimos firmados entre o banco e o Estado de Minas Gerais a partir de 2006, assim como os PMDIs publicados entre 2003 e 2012.

\section{O Banco Mundial}

O Banco Mundial é uma organização intergovernamental composta por aproximadamente 190 Estados-membros e com atuação em mais de 100 países. Foi criado como Banco Internacional de Reconstrução e Desenvolvimento (BIRD) para a Europa após a Segunda Guerra Mundial e passou a atuar no apoio ao desenvolvimento dos países periféricos somente no fim dos anos de 1950, no âmbito da Guerra Fria (WORLD BANK, 2014).

Atualmente, seu principal objetivo é reduzir a pobreza em países em desenvolvimento e subdesenvolvidos a partir do fomento do crescimento sustentável (WORLD BANK, 2014). Porém, durante sua história, tanto os objetivos como a forma de atuar do banco sofreram grandes mudanças.

Em suas três primeiras décadas de existência, a atuação do BIRD se centrou, de maneira geral, no financiamento de projetos de infraestrutura, desenvolvimento agrícola e industrial, educação, planejamento familiar e combate direto à pobreza. Em meados da década de 1970, porém, o quadro de estagflação nos países ricos e as crises de endividamento nos países pobres, em grande parte, consequência dos choques do petróleo, levou o banco a repensar sua estratégia de atuação (BRESSER-PEREIRA, 1995).

Percebeu-se, naquele momento, que os empréstimos anteriores, voltados para projetos de infraestrutura, pouco contribuíam para corrigir as distorções da estrutura produtiva dos países financiados, e que o sucesso de um projeto não era suficiente 
para gerar desenvolvimento se os obstáculos estruturais ao crescimento não fossem corrigidos (STIGLITZ, 1999). Ou seja, em um país com condições estruturais ruins, mesmo um projeto bem-sucedido poderia não gerar os impactos esperados. A partir de tal constatação, é criado, ainda em 1979, o empréstimo de ajuste estrutural. Esse instrumento se diferenciava dos empréstimos para investimentos pelo fato de financiar políticas públicas e não projetos de investimento específicos.

Nesse período, o Banco Mundial passa a se valer cada vez mais das condicionantes, instrumentos que vinculam o recebimento de recursos à realização de certas ações consideradas essenciais pelo agente financiador. Segundo BresserPereira (1995), a crise da dívida gerou uma oportunidade para o banco impor condicionantes aos países subdesenvolvidos e, assim, influenciar as políticas econômicas locais, garantindo que diretrizes consideradas corretas pelos países ricos fossem seguidas. Seguindo a tendência de aprofundamento, nas décadas seguintes, as condicionantes passam a tratar de temas mais amplos, como a governança, reformas judiciais e a corrupção. Segundo Dreher (2004), entre 1980 e 1982, os programas de ajuste do BIRD possuíam em média 34 condicionantes. Já entre 1987 e 1990, a média passou a 56.

Ao identificar no Estado os fundamentos da crise, o BIRD passou a pressionar os países menos desenvolvidos a adotarem diversas medidas, posteriormente denominadas Consenso de Washington, centradas em: políticas comerciais e de preço, com abertura dos mercados e da utilização de preços internacionais; políticas de poupança e investimento, com a promoção da desregulação do setor financeiro e do investimento privado; política orçamentária, que deveria trazer a diminuição dos gastos públicos improdutivos e do gasto unitário dos programas sociais; e reformas institucionais, por intermédio do aumento da eficiência ou privatização das empresas públicas e pelo aumento da participação do setor privado na produção dos bens públicos (LICHTENSZTEJN, 2010; RUGER, 2005).

John Williamson (2004) definiu o Consenso de Washington como uma lista de dez reformas estruturais específicas que as instituições sediadas em Washington (FMI, Banco Mundial etc.) consideravam como precondição para os países ainda pobres, em particular da América Latina, retomarem o crescimento. As dez áreas definidas pelo Consenso eram: disciplina fiscal; reorientação dos gastos públicos; reforma tributária; privatização; desregulamentação; liberalização comercial; liberalização financeira; investimento direto estrangeiro; regime cambial competitivo; e propriedade intelectual. Destarte, as práticas já eram comuns nos programas de reforma da década passada (CHIARI, 2000; BÉJAR, 2002). 
Nesse período, surgem os programas de ajustes estruturais de segunda geração, que agora, além das dez diretrizes originais, apresentavam maior foco na melhoria das instituições, devido ao reconhecimento de sua influência nos resultados das reformas de ajustes estruturais (RODRIK, 2006).

A segunda geração de ajustes também serviu ao propósito de reconciliar Estado e mercado. O enfoque do BIRD vai do Estado mínimo, defendido nos anos 1980, para o Estado eficiente. Reconheceu-se naquele momento que o Estado cumpria um importante papel na criação das condições econômicas, sociais e institucionais essenciais para o florescimento do mercado. Assim, o banco passa a defender a transição da administração pública do modelo burocrático para o gerencial, tornando o Estado um provedor de bens públicos e um regulador do desenvolvimento (SANTOS JUNIOR, 2010).

No início da década de 2000, principalmente a partir de 2003, era forte a percepção que o Consenso de Washington havia falhado. Eram raros os casos de sucesso resultantes da aplicação das medidas prescritas. Eventos como a incapacidade de os países africanos realizarem o take-off, apesar das reformas realizadas, e as sucessivas crises financeiras na América Latina, Leste Asiático, Rússia e Turquia fortaleceram a percepção de fracasso do Consenso (CYPHER, 1998; RODRIK, 2006).

Ademais, conforme sustenta Ravallion (2016, p. 87), o Consenso de Washington era considerado

previsível demais para ser crível como uma prescrição política. Ele listava um conjunto único de políticas, mas os governos dos países em desenvolvimento viam que havia múltiplos caminhos para o sucesso do desenvolvimento. Em particular, a rota alternativa ao Consenso de Washington tomada pela China desde os anos 1980 era um exemplo para todos verem ${ }^{4}$.

Apesar de a maioria dos países terem se comprometido com a implementação dos ditames do Consenso, a América Latina alcançou um crescimento do PIB per capita médio no período entre 1991 e 2000 de apenas 1,62\% ao ano, nível superior apenas ao da África Subsaariana, e muito abaixo dos 7,07\% ao ano alcançados no Leste Asiático. Além do desempenho do PIB, o fluxo de investimentos para a região não se deu da forma prevista e o saldo na balança comercial apresentou

4 No original: "too formulaic to be credible as a policy prescription. It listed a single set of policies, but governments of developing countries see for themselves that there were multiple paths to development success. In particular, the non-Washington Consensus route taken by China since 1980 stood an example for all to see”. 
sucessivos déficits, contribuindo para a deterioração da situação fiscal via balanço de pagamentos (ANCOCHEA, 2009; BÉJAR, 2002; CYPHER, 1998) $)^{5}$.

É nesse contexto que o Banco Mundial lança, em 2005, um documento denominado Economic Growth in the 1990s: Learning from a Decade of Reform (WORLD BANK, 2005a). Nele, o banco se distancia definitivamente do Consenso de Washington ao afirmar que não há fórmulas universais para o desenvolvimento. Pelo contrário, o documento aponta para a humildade, a diversidade de reformas, a seletividade e a experimentação. Ressaltou-se a importância de levar em conta o contexto em que serão aplicadas as reformas, já que, em contextos diferentes, problemas iguais podem ter soluções distintas. Posteriormente, Robert Zoellick, presidente do banco entre 2007 e 2012, reforça essa posição ao defender que o Banco Mundial deveria aceitar o pluralismo e as políticas de desenvolvimento pautadas pela prática e não apenas pela visão da academia (ENNS, 2015; RODRIK, 2006; STIGLITZ, 2008).

No campo prático, a primeira metade dos anos 2000 também trouxe uma importante mudança nos instrumentos de empréstimo do banco. Em 2004, o Banco Mundial cria o Empréstimo para Política de Desenvolvimento (do inglês, Development Policy Loan - DPL). Em um contraponto aos empréstimos de ajuste estrutural, governados pelo Consenso de Washington, os DPLs não mais prescrevem um conjunto único de reformas a ser seguido. Ao contrário, a partir da percepção de que as reformas só teriam sucesso se o país financiado considerasse que sua realização estava no seu melhor interesse, o banco passa a financiar os programas de reforma criados e apoiados internamente. Isto se deve, em grande parte, a estudos que demonstraram que a aplicação de condicionantes nos empréstimos tinha baixa efetividade. Com isso, as condicionantes se tornam mais restritas, abordando apenas os pontos considerados críticos para o sucesso do programa (PALONI; ZANARDI, 2005) ${ }^{6}$.

Outra mudança relevante que teve início nesse período e ganhou força no banco desde então, foi a renovação do foco no combate à pobreza. O atual presidente (2012 - presente) do Banco Mundial, Jim Yong Kim, apresenta a erradicação da pobreza até 2030 e o aumento da prosperidade entre os $40 \%$ mais pobres nos países em desenvolvimento e subdesenvolvidos como a dupla missão da instituição.

5 O período pós-Consenso na América Latina também é conhecido como “pós-liberal” ou "contencioso de Washington”. Para maior profundidade nesse assunto, ver Marangos (2008), Montiel (2007), Fine, Lapavitsas e Pincus (2001) e Katz (2015).

6 Segundo Ravallion (2016), atualmente cerca de um quarto dos empréstimos do BIRD envolvem os DPLs. 
Tal foco justifica em grande parte a continuidade dos empréstimos para países em um estágio de desenvolvimento um pouco mais avançado, como Brasil e México, por exemplo. Segundo Ravallion, nos últimos 15 anos, o aumento do gasto com proteção social nos países em desenvolvimento teve amplo apoio financeiro do Banco Mundial (CLEMENS e KREMER, 2016; RAVALLION, 2016).

\section{Condicionantes, Ownership e Seletividade}

A partir do reconhecimento da limitada eficiência da aplicação de condicionantes, o Banco Mundial passa a adotar conceitos como ownership e seletividade como partes centrais de seus programas de empréstimo e ajuda. Abordaremos tais conceitos e discutiremos como essas novas ideias influenciaram a atuação do Banco Mundial.

O termo condicionante diz respeito ao processo através do qual as instituições financeiras internacionais fazem empréstimos com base no compromisso do mutuário de promover certo conjunto de políticas públicas (SACHS, 1989). É dizer, uma condicionante vincula o recebimento de certos benefícios à realização de um conjunto de ações, sejam elas reformas institucionais ou a implementação de políticas públicas, de forma prévia ou posterior ao empréstimo.

Desde que começaram a ser utilizadas com maior frequência na década de 1980, as condicionantes se tornaram um tema polêmico, sendo analisadas e criticadas por serem intrusivas, corrosivas e ineficientes (KOEBERLE, 2003). Segundo Drazen (2006), o debate sobre condicionantes gerou questões tanto de cunho pragmático quanto conceitual. No campo pragmático, as principais questões apresentadas foram: “Quão efetivas são as condicionantes em ajudar os programas de assistência do FMI ou do Banco Mundial em alcançar seus objetivos? E como elas podem ser mais efetivas?7” (DRAZEN, 2006, p. 5). Por outro lado, no campo conceitual, o questionamento diz respeito a como deve ser a relação entre os organismos internacionais de financiamento e os países soberanos que recorrem aos empréstimos, sendo esta relação definida pela forma como as condicionantes são aplicadas.

As críticas quanto à efetividade das condicionantes, mais abundantes e complexas, tratam da capacidade (ou incapacidade) das instituições financeiras

7 No original: "How effective has conditionality been in helping IMF or World Bank assistance programs achieve their aims?, and How can it be made more effective?" 
internacionais de forçarem a realização de reformas que não ocorreriam em sua ausência. Segundo Santiso (2001), o fracasso das condicionantes em gerar reformas sustentáveis é de amplo conhecimento.

A principal fonte da ineficiência das condicionantes são os incentivos que o Banco Mundial tem para emprestar seus recursos. Segundo Dreher (2004), como o BIRD financia seus empréstimos com dinheiro proveniente do mercado de capitais, ele sofre uma forte pressão para emprestar os recursos que possui. Com isto, a liberação de recursos continua a tomar precedência sobre uma preocupação com o aumento da qualidade dos instrumentos de empréstimo e doações, das condicionantes que o acompanham e do impacto geral do programa na performance do mutuário (RANIS, 2006). Portanto, é fácil afirmar que não é interessante para o BIRD determinar critérios claros que poderiam resultar no cancelamento automático de um empréstimo. Dessa necessidade de emprestar seus recursos resulta, portanto, que o banco mundial quase nunca cancela o repasse de recursos, mesmo que as condições acordadas não sejam cumpridas (DREHER, 2004).

Devido à falta de vontade do banco de forçar o cumprimento das condicionantes de forma mais rígida, o próprio BIRD reconheceu que, quando não há o interesse do governo recipiente em realizar as medidas acordadas, as condicionantes costumam falhar (WORLD BANK, 2005b; KOEBERLE, 2003; RANIS, 2006). Esse interesse em realizar certo conjunto de reformas é denominado ownership. Segundo Koeberle (2003), quando falta ownership, as condicionantes são incapazes de levar à adoção de melhores políticas públicas. Diversos estudos empíricos demonstram que mudanças nas políticas públicas, em geral, são fruto da economia política do país e não de influências externas. Porém, se há compromisso e capacidade para realizar as reformas, os empréstimos condicionados podem "acelerar, ampliar e alargar as reformas, aumentando seu impacto e, possivelmente, contribuindo para o crescimento e desenvolvimento ${ }^{8}$ " (KOEBERLE, 2003. p. 258). Clemens e Kremer (2016) apontam o Bolsa Família e o Progresa, programas de transferência monetária condicionada do Brasil e do México, respectivamente, como exemplos desse efeito. Segundo o autor, apesar de se tratarem de inovações internas, a avaliação e a promoção desse tipo de política pelo Banco Mundial gerou legitimidade e credibilidade para os programas.

8 No original: "accelerate, broaden, and deepen it, enhancing its impact and hopefully contributing to growth and development”. 
Segundo o Banco Mundial, ownership pode ser definida como algo que "inclui forças políticas, econômicas e sociais, formais e informais, que determinam a prioridade que o governo, a sociedade civil e o setor privado dão a um objetivo de desenvolvimento9" (WORLD BANK, 2011, p. 7). Já Drazen (2006), em uma conceituação mais ampla, aponta que ownership pode "a grosso modo, ser definida como a medida em que um país está interessado em perseguir certas reformas independentemente de qualquer incentivo provido por credores multilaterais ${ }^{10}$ " (DRAZEN, 2006, p. 51).

Tal concepção gera algumas dúvidas quanto à compatibilidade da ownership com a utilização das condicionantes. É dizer, se um país está realmente interessado em promover certa política pública, por que haveria a necessidade de definir condicionantes para tal? Drazen (2006) acredita que a resposta está na heterogeneidade de interesses dentro do país que recebe o empréstimo. Ele defende que, muitas vezes, o governo interessado em promover certa reforma ou política pública pode sofrer oposições internas e, nesses casos, as condicionantes podem cumprir o papel de reforçar a posição do governo. Para ele, quando a ownership sobre as reformas é total, o uso de condicionantes é redundante e desnecessário. Quando ela é nula, as condicionantes não são capazes de influenciar a implementação das políticas ou reformas.

Com o reconhecimento que as condicionantes são efetivas apenas nos casos onde há alguma ownership sobre as medidas acordadas, mesmo que ela não seja unânime, passou-se a advogar por um aumento da seletividade na alocação dos empréstimos do Banco Mundial (KOEBERLE, 2003). Se a ownership sobre as políticas condicionadas é necessária para a efetividade de um programa, então o BIRD deveria emprestar somente para os países que demonstram genuíno interesse em implementá-las.

Koeberle (2003) defende que a seletividade apenas mudaria o foco da tensão entre os países e o BIRD, do momento da negociação das condicionantes para o momento da avaliação anterior ao início da negociação de um empréstimo. Posição parcialmente apoiada por Morrow (2005), que acredita que países sem acesso a outras fontes de financiamento, e com alta necessidade de captar recursos, sofreriam uma forte pressão para aceitar ou fingir aceitar as reformas propostas pelo

9 No original: "Stakeholder ownership comprises formal and informal political, economic and social forces that determine the priority that government, civil society and the private sector give to a development goal."

10 No original: "may be roughly defined as the extent to which a country is interested in pursuing reforms independently of any incentives provided by multilateral lenders". 
Banco Mundial, sob pena de não terem acesso a qualquer fonte de financiamento. Portanto, a seletividade criaria incentivos para que possíveis mutuários adotassem (ou fingissem adotar) um conjunto de estratégias e reformas condizentes com a cartilha do BIRD, visando ter acesso a suas linhas de financiamento.

Na próxima seção, passaremos, então, a analisar o relacionamento entre o Estado de Minas Gerais e o Banco Mundial à luz desses conceitos.

\section{O Banco Mundial e o Estado De Minas Gerais}

Nesta seção abordaremos os quatro empréstimos relacionados às Parcerias para o Desenvolvimento de Minas Gerais, firmadas a partir de 2006. Visto que apresentamos a hipótese que o banco exerce sua influência por meio das condicionantes, não seria relevante analisar os demais empréstimos contratados por Minas Gerais, já que eles financiaram projetos de investimentos específicos e, por isso, possuíam baixa capacidade de influenciar a estratégia de desenvolvimento governamental.

Em nossa análise, verificaremos a aderência dos objetivos de cada empréstimo e de suas respectivas condicionantes com os objetivos estratégicos do Estado de Minas Gerais. Para tanto, contrastaremos o Plano Mineiro de Desenvolvimento Integrado - PMDI ${ }^{11}$, com os documentos dos empréstimos, publicados pelo Banco Mundial. A escolha do PMDI se deu não só por ser o documento que apresenta a visão estratégica de longo prazo do governo, e que serve de base para a elaboração dos demais planos governamentais, mas também por apresentar um conteúdo profundo e abrangente.

\section{A Parceria para o Desenvolvimento de Minas Gerais}

Em abril de 2006, o governo de Minas Gerais e o Banco Mundial assinam o contrato de empréstimo intitulado Parceria para o Desenvolvimento de Minas Gerais. Mediante essa operação, o BIRD emprestou US\$ 170 milhões ao estado, com o objetivo de dar suporte e aprofundar as reformas iniciadas com o Choque de Gestão, buscando melhorar o balanço fiscal, a efetividade do setor público e o desenvolvimento do setor privado (WORLD BANK, 2006).

11 O PMDI apresenta a visão de longo prazo do governo, assim como os objetivos prioritários para que se alcance o futuro desejado. Dentro de cada objetivo estratégico, são apresentadas diversas metas que permitiriam a realização do objetivo (MINAS GERAIS, 2003). 
Para essa operação, o instrumento utilizado foi o recém-criado DPL. Em geral, esse instrumento é utilizado para dar suporte a um programa de reformas institucionais ou ao desenvolvimento de políticas econômicas e setoriais consideradas satisfatórias pelo Banco Mundial. A utilização do DPL para o financiamento da Parceria representou um marco na atuação do BIRD no Brasil - esse foi o primeiro Empréstimo para Política de Desenvolvimento feito para um ente subnacional no país (WORLD BANK, 2006).

Com relação à estrutura do empréstimo, a Parceria para o Desenvolvimento de Minas Gerais possuía dois desembolsos, cada qual com suas condicionantes específicas. Uma das mudanças instituídas pelo DPL foi substituir as condicionantes ex post em favor de condicionantes prévias à realização do empréstimo. O primeiro desembolso tinha um valor de US\$100 milhões e deveria ser pago assim que o empréstimo entrasse em efeito. A liberação destes recursos estava condicionada ao cumprimento dos ditames da Lei de Responsabilidade Fiscal e do acordo de refinanciamento da dívida pública celebrado com a Secretaria do Tesouro Nacional (STN). Pode-se dizer, entretanto, que tal condicionante tinha caráter meramente formal, já que elas haviam sido cumpridas anteriormente à sua estipulação. Já a segunda liberação somava US\$ 70 milhões e estava condicionada ao alcance de todos os indicadores apresentados no Quadro 1 (WORLD BANK, 2006).

O alinhamento entre as ações apoiadas pela Parceria para o Desenvolvimento de Minas Gerais, as condicionantes definidas em contrato e os objetivos estratégicos do governo estadual constantes no PMDI 2003-2020 estão sintetizados abaixo. O Quadro 1 apresenta as áreas apoiadas pelo empréstimo seguidas pelos indicadores que condicionaram a liberação dos recursos, assim como as estratégias correspondentes definidas pelo governo no PMDI. 


\section{Quadro 1. Comparativo entre a Parceria para o Desenvolvimento de Minas} Gerais (2006) e o Plano Mineiro de Desenvolvimento Integrado - 2003-2020

\begin{tabular}{|c|c|c|c|}
\hline \multicolumn{2}{|c|}{$\begin{array}{l}\text { Parceria para o Desenvolvimento } \\
\text { de Minas Gerais }\end{array}$} & \multicolumn{2}{|c|}{$\begin{array}{l}\text { Plano Mineiro de Desenvolvimento } \\
\text { Integrado (2003-2020) }\end{array}$} \\
\hline $\begin{array}{l}\text { Áreas apoiadas pelo } \\
\text { empréstimo }\end{array}$ & $\begin{array}{c}\text { Indicadores } \\
\text { (Condicionantes) }\end{array}$ & $\begin{array}{c}\text { Área de } \\
\text { Resultado }\end{array}$ & Estratégia \\
\hline $\begin{array}{l}\text { 1. Cumprimento do } \\
\text { acordo estabeleci- } \\
\text { do com o Governo } \\
\text { Federal através do } \\
\text { Programa de Ajuste } \\
\text { Fiscal - PAF - e da } \\
\text { Lei de Responsabili- } \\
\text { dade Fiscal }\end{array}$ & $\begin{array}{l}\text { Atingir um superávit primá- } \\
\text { rio de } \mathrm{R} \$ 1,596 \text { milhões em } \\
2005 \text { e reduzir o gasto com } \\
\text { pessoal para } 60 \% \text { ou menos }\end{array}$ & Choque de Gestão & $\begin{array}{l}\text { Implementar estratégias e } \\
\text { tecnologias de gerencia- } \\
\text { mento das receitas e das } \\
\text { despesas, objetivando o } \\
\text { equilíbrio fiscal }\end{array}$ \\
\hline $\begin{array}{l}\text { 2. Redução do Custo da } \\
\text { dívida pública }\end{array}$ & $\begin{array}{l}\text { Pré-pagamento de pelo me- } \\
\text { nos R } \$ 100 \text { milhões de reais } \\
\text { de débitos flutuantes ou } \\
\text { consolidados não cober- } \\
\text { tos pelo acordo de refinan- } \\
\text { ciamento da dívida com } \\
\text { o Tesouro Nacional e não } \\
\text { devidos ao BIRD }\end{array}$ & & \\
\hline $\begin{array}{l}\text { 3. Modernização da } \\
\text { Subsecretaria da Re- } \\
\text { ceita }\end{array}$ & $\begin{array}{l}\text { Instalar pelo menos sete } \\
\text { novos módulos de informa- } \\
\text { ções computadorizadas de } \\
\text { gestão de tributos (SIARE) }\end{array}$ & Choque de Gestão & $\begin{array}{l}\text { Modernizar e reestruturar } \\
\text { a Receita Estadual, para } \\
\text { o incremento da receita } \\
\text { fiscal do Estado }\end{array}$ \\
\hline $\begin{array}{l}\text { 4. Otimização da gestão } \\
\text { de recursos humanos }\end{array}$ & $\begin{array}{l}\text { Instalar o novo sistema in- } \\
\text { tegrado de pagamento de } \\
\text { pessoal (SISAP) }\end{array}$ & Choque de Gestão & $\begin{array}{l}\text { Revisar o modelo de ges- } \\
\text { tão de pessoas, mediante } \\
\text { a adoção de política de } \\
\text { carreiras, desenvolvimen- } \\
\text { to e de remuneração dos } \\
\text { servidores, vinculadas a } \\
\text { resultados - qualidade e } \\
\text { produtividade }\end{array}$ \\
\hline $\begin{array}{l}\text { 5. Implementação do } \\
\text { Estado para Resulta- } \\
\text { dos (Administração } \\
\text { por resultados) }\end{array}$ & $\begin{array}{l}\text { Assinar pelo menos um } \\
\text { acordo de resultados adi- } \\
\text { cional e revisar pelo menos } \\
\text { cinco acordos de resultados } \\
\text { com agências estatais }\end{array}$ & & $\begin{array}{l}\text { Disseminação da prática } \\
\text { de implementação e ge- } \\
\text { renciamento de projetos e } \\
\text { de programas focados em } \\
\text { resultados }\end{array}$ \\
\hline
\end{tabular}


(continuação)

\begin{tabular}{|c|c|c|c|}
\hline \multicolumn{2}{|c|}{$\begin{array}{l}\text { Parceria para o Desenvolvimento } \\
\text { de Minas Gerais }\end{array}$} & \multicolumn{2}{|c|}{$\begin{array}{l}\text { Plano Mineiro de Desenvolvimento } \\
\text { Integrado (2003-2020) }\end{array}$} \\
\hline $\begin{array}{l}\text { Áreas apoiadas pelo } \\
\text { empréstimo }\end{array}$ & $\begin{array}{c}\text { Indicadores } \\
\text { (Condicionantes) }\end{array}$ & $\begin{array}{c}\text { Área de } \\
\text { Resultado }\end{array}$ & Estratégia \\
\hline $\begin{array}{l}\text { 6. Eficiência e econo- } \\
\text { mia na gestão logís- } \\
\text { tica e de suprimentos }\end{array}$ & $\begin{array}{l}\text { Instalação do módulo SIAD } \\
\text { para método de preço de } \\
\text { compras públicas (pregão } \\
\text { eletrônico) }\end{array}$ & Choque de Gestão & $\begin{array}{l}\text { Implementar programas } \\
\text { de melhoria contínua de } \\
\text { processos, para introduzir } \\
\text { o conceito de qualidade } \\
\text { na administração pública, } \\
\text { com ênfase nos sistemas } \\
\text { informatizados corpora- } \\
\text { tivos }\end{array}$ \\
\hline $\begin{array}{l}\text { 7. Transparência e aces- } \\
\text { so a informações go- } \\
\text { vernamentais }\end{array}$ & $\begin{array}{l}\text { Lançamento do website de } \\
\text { planejamento e gestão com } \\
\text { um módulo para monito- } \\
\text { ramento da execução dos } \\
\text { programas estruturais }\end{array}$ & Choque de Gestão & $\begin{array}{l}\text { Implementar política de } \\
\text { tecnologia da informação } \\
\text { e de governo eletrônico, } \\
\text { com uso intensivo da in- } \\
\text { ternet para prestar ser- } \\
\text { viços e divulgar metas e } \\
\text { resultados. }\end{array}$ \\
\hline $\begin{array}{l}\text { 8. Melhoria do ambien- } \\
\text { te de investimentos }\end{array}$ & $\begin{array}{l}\text { Integrar a cobrança do } \\
\text { ICMS ao sistema SIARE } \\
\text { junto ao registro do Siste- } \\
\text { ma Integrado de Adminis- } \\
\text { tração de Materiais e Servi- } \\
\text { ços (SIAD) }\end{array}$ & Choque de Gestão & $\begin{array}{l}\text { Descomplicar Minas Ge- } \\
\text { rais, facilitando a vida do } \\
\text { empreendedor. }\end{array}$ \\
\hline $\begin{array}{l}\text { 9. Parcerias público- } \\
\text {-privadas (PPP) }\end{array}$ & $\begin{array}{l}\text { Desenhar um mecanismo } \\
\text { de garantias estatais para } \\
\text { as PPPs }\end{array}$ & $\begin{array}{l}\text { Viabilização de } \\
\text { novas formas de } \\
\text { financiamento dos } \\
\text { empreendimentos } \\
\text { públicos }\end{array}$ & $\begin{array}{l}\text { Estabelecer marco legal } \\
\text { estadual que possibilite } \\
\text { a contratação de servi- } \\
\text { ços públicos no conceito } \\
\text { PPP - Parceria Público- } \\
\text {-Privada. }\end{array}$ \\
\hline
\end{tabular}

Fonte: Minas Gerais, 2003; World Bank, 2006 - elaboração própria.

A análise do quadro demonstra que as condicionantes do empréstimo mantiveram uma alta aderência ao PMDI, o que sugere que elas não serviram ao propósito de forçar o Estado a realizar reformas que não possuíam ownership, já que as medidas condicionadas faziam parte do plano estratégico previamente apresentado pelo governo de Minas Gerais.

\section{A Segunda Parceira para o Desenvolvimento de Minas Gerais}

A Segunda Parceria para o Desenvolvimento de Minas Gerais representou um aprofundamento na relação entre o Estado e o Banco Mundial, tanto em 
termos financeiros como em apoio técnico e troca de conhecimentos. O primeiro empréstimo dessa parceria, assinado em agosto de 2008, tinha o valor de US\$ 976 milhões. Segundo o Project Appraisal Document - relatório no qual o BIRD descreve o contexto, os objetivos, as ações e tudo aquilo considerado relevante ao empréstimo -, o governo de Minas Gerais solicitou a ajuda do Banco na implementação e aprofundamento da Gestão por Resultados nas principais secretarias setoriais. Para tanto, o BIRD daria apoio a três objetivos amplos do governo: melhorar a qualidade fiscal; desenvolver a qualidade e a inovação no setor público; e aperfeiçoar o controle e o monitoramento de resultados (WORLD BANK, 2008b).

Os três objetivos mencionados acima seriam aplicados em seis áreas de resultados definidas no Estado para Resultados, nome dado à segunda fase das reformas de Minas Gerais, com foco na melhoria dos serviços públicos e no crescimento econômico. Para cada área, governo e banco acordaram alguns indicadores que condicionariam o reembolso das despesas elegíveis. No total, foram escolhidos 24 indicadores que já constavam no Acordo de Resultados governamental, o que garantiu seu alinhamento com a estratégia do Estado e a capacidade desse de monitorá-los (WORLD BANK, 2008b).

No ano de 2010, oito novos indicadores nas áreas de qualidade ambiental e social, e alívio da pobreza foram incluídos na parceria e algumas das metas iniciais atualizadas. Essa alteração se dá devido à contratação de um financiamento adicional à Segunda Parceria para o Desenvolvimento de Minas Gerais. O novo empréstimo, realizado devido à perda de arrecadação resultante da crise mundial de 2008, teve um valor total de US\$ 461 milhões. Vale ressaltar que o novo empréstimo visou somente garantir que as reformas que estavam sendo empreendidas não fossem prejudicadas pela diminuição dos recursos disponíveis (WORLD BANK, 2010).

Assim como no caso da primeira Parceria para o Desenvolvimento de Minas Gerais, uma análise do PMDI 2007-2023 deixa claro que os projetos estratégicos financiados e as condicionantes mantiveram um alinhamento com os objetivos prioritários de longo prazo do governo. O Quadro 2, que contém os 32 indicadores como definidos no financiamento adicional à Segunda Parceria, demonstra tal situação. 


\section{Quadro 2. Comparativo entre a Segunda Parceria para o Desenvolvimento de} Minas Gerais (2008) e o Plano Mineiro de Desenvolvimento Integrado - 2007-2023

\begin{tabular}{|c|c|c|c|c|}
\hline \multicolumn{3}{|c|}{$\begin{array}{c}\text { Segunda Parceria para o Desenvolvimento } \\
\text { de Minas Gerais (2008) }\end{array}$} & \multicolumn{2}{|c|}{$\begin{array}{l}\text { Plano Mineiro de Desenvolvimento Integrado } \\
\qquad(2007-2023)\end{array}$} \\
\hline $\begin{array}{l}\text { Áreas apoiadas } \\
\text { pelo empréstimo }\end{array}$ & $\begin{array}{l}\text { Projetos } \\
\text { estratégicos }\end{array}$ & $\begin{array}{l}\text { Indicadores ligados } \\
\text { aos desembolsos } \\
\text { (Condicionantes) }\end{array}$ & $\begin{array}{l}\text { Área de } \\
\text { Resultado }\end{array}$ & Estratégia \\
\hline \multirow{9}{*}{ SETOR PÚBLICO } & $\begin{array}{l}\text { Choque de Gestão } \\
\text { Setorial }\end{array}$ & $\begin{array}{l}\text { Implementação dos } \\
\text { Acordos de Resultados } \\
\text { de } 1^{\text {a }} \text { etapa }\end{array}$ & \multirow{3}{*}{$\begin{array}{l}\text { Qualidade e Ino- } \\
\text { vação em Gestão } \\
\text { Pública }\end{array}$} & $\begin{array}{l}\text { Consolidar o Choque de Gestão } \\
\text { em todos os setores do Governo } \\
\text { Estadual e adensar seus benefícios } \\
\text { em transformações efetivas para a } \\
\text { sociedade mineira, com ênfase na } \\
\text { geração de resultados mensuráveis } \\
\text { nas Áreas de Resultados definidas }\end{array}$ \\
\hline & $\begin{array}{l}\text { Choque de Gestão } \\
\text { Setorial }\end{array}$ & $\begin{array}{l}\text { Implementação dos } \\
\text { Acordos de Resultados } \\
\text { de } 2^{\text {a }} \text { Etapa }\end{array}$ & & $\begin{array}{l}\text { Consolidar o Choque de Gestão } \\
\text { em todos os setores do Governo } \\
\text { Estadual e adensar seus benefícios } \\
\text { em transformações efetivas para a } \\
\text { sociedade mineira, com ênfase na } \\
\text { geração de resultados mensuráveis } \\
\text { nas Áreas de Resultados definidas }\end{array}$ \\
\hline & $\begin{array}{l}\text { Profissionalização } \\
\text { dos Gestores Pú- } \\
\text { blicos }\end{array}$ & $\begin{array}{l}\text { Certificação de funções } \\
\text { no Setor Público }\end{array}$ & & $\begin{array}{l}\text { Melhorar a qualidade dos serviços } \\
\text { prestados pelas instituições públi- } \\
\text { cas mineiras, por meio da } \\
\text { seleção, formação e desenvolvi- } \\
\text { mento de gestores públicos pro- } \\
\text { fissionais }\end{array}$ \\
\hline & $\begin{array}{l}\text { Modernização da } \\
\text { Gestão Fiscal }\end{array}$ & $\begin{array}{l}\text { Indicadores do Progra- } \\
\text { ma de Ajuste Fiscal do } \\
\text { Estado de Minas Gerais } \\
\text { (PAF) firmado com a } \\
\text { STN (Superávit primá- } \\
\text { rio e razão entre des- } \\
\text { pesa de pessoal e RCL) }\end{array}$ & \multirow{4}{*}{ Qualidade Fiscal } & $\begin{array}{l}\text { Manter o compromisso com o } \\
\text { equilíbrio fiscal, aprimorando a } \\
\text { prevenção e a mitigação de riscos } \\
\text { de gestão }\end{array}$ \\
\hline & - & $\begin{array}{l}\text { Balanço Operacional } \\
\text { bruto }\end{array}$ & & $\begin{array}{l}\text { Estabilizar e iniciar a redução da } \\
\text { despesa orçamentária como pro- } \\
\text { porção do PIB estadual, passo que } \\
\text { antecede uma política sustentável } \\
\text { de redução da carga tributária }\end{array}$ \\
\hline & - & $\begin{array}{l}\text { Participação dos Proje- } \\
\text { tos Estruturadores na } \\
\text { despesa orçamentária }\end{array}$ & & $\begin{array}{l}\text { Aumentar a aderência do orçamen- } \\
\text { to à estratégia de médio prazo, am- } \\
\text { pliando a participação dos Projetos } \\
\text { Estruturadores na despesa total }\end{array}$ \\
\hline & $\begin{array}{l}\text { Qualidade e pro- } \\
\text { dutividade do gas- } \\
\text { to setorial }\end{array}$ & $\begin{array}{l}\text { Gestão do sistema de } \\
\text { compras }\end{array}$ & & $\begin{array}{l}\text { Ampliar a qualidade e a produtivi- } \\
\text { dade dos gastos setoriais }\end{array}$ \\
\hline & - & $\begin{array}{l}\text { Aprimoramento da ges- } \\
\text { tão por resultados }\end{array}$ & - & - \\
\hline & - & $\begin{array}{l}\text { Fortalecimento da for- } \\
\text { mulação de políticas } \\
\text { públicas }\end{array}$ & - & - \\
\hline
\end{tabular}


(continuação)

\begin{tabular}{|c|c|c|c|c|}
\hline \multicolumn{3}{|c|}{$\begin{array}{c}\text { Segunda Parceria para o Desenvolvimento } \\
\text { de Minas Gerais (2008) }\end{array}$} & \multicolumn{2}{|c|}{$\begin{array}{l}\text { Plano Mineiro de Desenvolvimento Integrado } \\
\qquad(2007-2023)\end{array}$} \\
\hline $\begin{array}{l}\text { Áreas apoiadas } \\
\text { pelo empréstimo }\end{array}$ & $\begin{array}{l}\text { Projetos } \\
\text { estratégicos }\end{array}$ & $\begin{array}{l}\text { Indicadores ligados } \\
\text { aos desembolsos } \\
\text { (Condicionantes) }\end{array}$ & $\begin{array}{l}\text { Área de } \\
\text { Resultado }\end{array}$ & Estratégia \\
\hline \multirow{4}{*}{ SETORPRIVADO } & $\begin{array}{l}\text { Simplificação dos } \\
\text { negócios }\end{array}$ & $\begin{array}{l}\text { Tempo para Abertura } \\
\text { de uma Empresa atra- } \\
\text { vés do Minas Fácil }\end{array}$ & \multirow{2}{*}{$\begin{array}{l}\text { Investimento e } \\
\text { Valor Agregado } \\
\text { da Produção }\end{array}$} & \multirow{2}{*}{$\begin{array}{l}\text { Simplificar a relação do setor pú- } \\
\text { blico com o setor privado }\end{array}$} \\
\hline & $\begin{array}{l}\text { Simplificação dos } \\
\text { negócios }\end{array}$ & $\begin{array}{l}\text { Implementação do Mi- } \\
\text { nas Fácil em todo o } \\
\text { estado }\end{array}$ & & \\
\hline & $\begin{array}{l}\text { Parcerias público- } \\
\text { privadas (PPPs) }\end{array}$ & $\begin{array}{l}\text { Número de projetos de } \\
\text { PPPs contratados }\end{array}$ & - & - \\
\hline & $\begin{array}{l}\text { Rede de inovação } \\
\text { e tecnologia }\end{array}$ & $\begin{array}{l}\text { Núcleos de Inovação } \\
\text { Tecnológica }\end{array}$ & $\begin{array}{l}\text { Inovação, Tecno- } \\
\text { logia e Qualidade }\end{array}$ & $\begin{array}{l}\text { Fortalecer a rede de inovação } \\
\text { tecnológica em todo o território } \\
\text { mineiro }\end{array}$ \\
\hline \multirow{3}{*}{ SAÚDE } & $\begin{array}{l}\text { Regionalização } \\
\text { dos serviços de } \\
\text { saúde }\end{array}$ & $\begin{array}{l}\text { Percentual de hospitais } \\
\text { do programa PROHOSP } \\
\text { formalmente avaliados } \\
\text { para acreditação pela } \\
\text { ONA }\end{array}$ & \multirow{3}{*}{ Vida Saudável } & $\begin{array}{l}\text { Intensificar o processo de regio- } \\
\text { nalização da Atenção à Saúde, } \\
\text { para, progressivamente, adequar } \\
\text { a oferta e a qualidade da atenção } \\
\text { de média e alta complexidade às } \\
\text { necessidades da população }\end{array}$ \\
\hline & - & $\begin{array}{l}\text { Implementação de um } \\
\text { sistema padronizado } \\
\text { de custos em hospitais } \\
\text { da FHEMIG }\end{array}$ & & $\begin{array}{l}\text { Aumentar a eficiência alocativa e a } \\
\text { otimização do sistema de atenção } \\
\text { à saúde. }\end{array}$ \\
\hline & Saúde em Casa & $\begin{array}{l}\text { Estudo de impacto dos } \\
\text { Centros Viva Vida }\end{array}$ & & $\begin{array}{l}\text { Universalizar a oferta para a popu- } \\
\text { lação SUS dependente e ampliar a } \\
\text { qualidade dos serviços de atenção } \\
\text { primária à saúde, com ênfase em } \\
\text { ações de promoção, prevenção e } \\
\text { assistência à saúde da família }\end{array}$ \\
\hline \multirow{4}{*}{ EDUCAÇÃO } & $\begin{array}{l}\text { Alfabetização no } \\
\text { Tempo Certo }\end{array}$ & $\begin{array}{l}\text { Percentual de alunos } \\
\text { da rede estadual em } \\
\text { nível recomendável de } \\
\text { leitura no } 3^{\circ} \text { ano do EF }\end{array}$ & \multirow{3}{*}{$\begin{array}{l}\text { Educação de Qua- } \\
\text { lidade }\end{array}$} & $\begin{array}{l}\text { Reduzir a taxa de distorção idade/ } \\
\text { série }\end{array}$ \\
\hline & $\begin{array}{l}\text { Sistema de Avalia- } \\
\text { ção da Rede Pú- } \\
\text { blica de Educação } \\
\text { Básica - PROEB }\end{array}$ & $\begin{array}{l}\text { Programa de Avaliação } \\
\text { da Aprendizagem Es- } \\
\text { colar }\end{array}$ & & $\begin{array}{l}\text { A construção de sistemas de ava- } \\
\text { liação, com o objetivo de verificar } \\
\text { periodicamente a qualidade do } \\
\text { ensino em todas as escolas de } \\
\text { Minas Gerais e subsidiar a gestão } \\
\text { escolar orientada para resultados* }\end{array}$ \\
\hline & - & $\begin{array}{l}\text { Sistema de Informações } \\
\text { Custo-Aluno (SICA) }\end{array}$ & & $\begin{array}{l}\text { Promover um salto na escolari- } \\
\text { dade média da população, for- } \\
\text { mada em um sistema eficiente, } \\
\text { com altos níveis de equidade e } \\
\text { orientado por padrões internacio- } \\
\text { nais de custo e qualidade }\end{array}$ \\
\hline & $\begin{array}{l}\text { Educação profis- } \\
\text { sionalizante }\end{array}$ & $\begin{array}{l}\text { Estudantes matricula- } \\
\text { dos em cursos de en- } \\
\text { sino médio profissio- } \\
\text { nalizante }\end{array}$ & $\begin{array}{l}\text { Protagonismo Ju- } \\
\text { venil }\end{array}$ & $\begin{array}{l}\text { Ampliar a oferta e melhorar a } \\
\text { qualidade do Ensino Profissiona- } \\
\text { lizante* }^{*}\end{array}$ \\
\hline
\end{tabular}

(continua...) 
(continuação)

\begin{tabular}{|c|c|c|c|c|}
\hline \multicolumn{3}{|c|}{$\begin{array}{c}\text { Segunda Parceria para o Desenvolvimento } \\
\text { de Minas Gerais (2008) }\end{array}$} & \multicolumn{2}{|c|}{$\begin{array}{l}\text { Plano Mineiro de Desenvolvimento Integrado } \\
\qquad(2007-2023)\end{array}$} \\
\hline $\begin{array}{l}\text { Áreas apoiadas } \\
\text { pelo empréstimo }\end{array}$ & $\begin{array}{l}\text { Projetos } \\
\text { estratégicos }\end{array}$ & $\begin{array}{l}\text { Indicadores ligados } \\
\text { aos desembolsos } \\
\text { (Condicionantes) }\end{array}$ & $\begin{array}{c}\text { Área de } \\
\text { Resultado }\end{array}$ & Estratégia \\
\hline \multirow{4}{*}{$\begin{array}{l}\text { INFRAESTRUTURA } \\
\text { RODOVIÁRIA }\end{array}$} & $\begin{array}{l}\text { ProMG Pleno - } \\
\text { Recuperação e } \\
\text { manutenção de } \\
\text { rodovias }\end{array}$ & $\begin{array}{l}\text { Percentual da malha } \\
\text { rodoviária estadual pa- } \\
\text { vimentada com contra- } \\
\text { tos de manutenção e } \\
\text { reabilitação por resul- } \\
\text { tado no Pró-MG Pleno }\end{array}$ & \multirow{4}{*}{$\begin{array}{l}\text { Logística de Inte- } \\
\text { gração e Desen- } \\
\text { volvimento }\end{array}$} & $\begin{array}{l}\text { Reduzir os custos de transportes } \\
\text { e ampliar o acesso a mercados da } \\
\text { produção mineira, através da ofer- } \\
\text { ta de uma malha viária suficiente, } \\
\text { adequada e segura }\end{array}$ \\
\hline & Pro-Acesso & $\begin{array}{l}\text { Percentual médio de } \\
\text { atraso das obras de } \\
\text { pavimentação do Pró- } \\
\text { Acesso concluídas no } \\
\text { ano corrente }\end{array}$ & & $\begin{array}{l}\text { Superar gargalos e melhorar a qua- } \\
\text { lidade da infraestrutura de trans- } \\
\text { portes, para ampliar a inserção } \\
\text { competitiva da economia mineira } \\
\text { e o desenvolvimento das regiões } \\
\text { de baixo dinamismo }\end{array}$ \\
\hline & ProSeg & $\begin{array}{l}\text { Número de equipa- } \\
\text { mentos eletrônicos de } \\
\text { controle de velocidade }\end{array}$ & & $\begin{array}{l}\text { Reduzir os custos de transportes } \\
\text { e ampliar o acesso a mercados da } \\
\text { produção mineira, através da ofer- } \\
\text { ta de uma malha viária suficiente, } \\
\text { adequada e segura }\end{array}$ \\
\hline & Pro-Acesso & $\begin{array}{l}\text { Percentual de muni- } \\
\text { cípios no estado com } \\
\text { acesso pavimentado }\end{array}$ & & $\begin{array}{l}\text { Superar gargalos e melhorar a qua- } \\
\text { lidade da infraestrutura de trans- } \\
\text { portes, para ampliar a inserção } \\
\text { competitiva da economia mineira } \\
\text { e o desenvolvimento das regiões } \\
\text { de baixo dinamismo }\end{array}$ \\
\hline \multirow{3}{*}{$\begin{array}{l}\text { QUALIDADE } \\
\text { AMBIENTAL } \\
\text { E SOCIAL }\end{array}$} & $\begin{array}{l}\text { Implementação } \\
\text { do SISEMA Móvel } \\
\text { e qualificação de } \\
\text { pessoal }\end{array}$ & $\begin{array}{l}\text { Tempo médio para a } \\
\text { concessão de licença } \\
\text { ambiental (LI e LO para } \\
\text { as classes } 3 \text { e 4) para } \\
\text { atividades com impac- } \\
\text { to ambiental no estado. }\end{array}$ & $\begin{array}{l}\text { Qualidade Ambi- } \\
\text { ental }\end{array}$ & $\begin{array}{l}\text { Adotar metas de sustentabilidade } \\
\text { e qualidade ambiental e consolidar } \\
\text { o sistema de monitoramento }\end{array}$ \\
\hline & Saúde Indígena & $\begin{array}{l}\text { Número de equipes } \\
\text { interdisciplinares para } \\
\text { saúde indígena finan- } \\
\text { ciadas pela SES }\end{array}$ & - & - \\
\hline & $\begin{array}{l}\text { Educação Indíge- } \\
\text { na }\end{array}$ & $\begin{array}{l}\text { Número de professores } \\
\text { certificados no Curso } \\
\text { de Magistério Indígena }\end{array}$ & - & - \\
\hline
\end{tabular}

(continua...) 
(continuação)

\begin{tabular}{|c|c|c|c|c|}
\hline \multicolumn{3}{|c|}{$\begin{array}{c}\text { Segunda Parceria para o Desenvolvimento } \\
\text { de Minas Gerais (2008) }\end{array}$} & \multicolumn{2}{|c|}{$\begin{array}{l}\text { Plano Mineiro de Desenvolvimento Integrado } \\
\qquad(2007-2023)\end{array}$} \\
\hline $\begin{array}{l}\text { Áreas apoiadas } \\
\text { pelo empréstimo }\end{array}$ & $\begin{array}{l}\text { Projetos } \\
\text { estratégicos }\end{array}$ & $\begin{array}{l}\text { Indicadores ligados } \\
\text { aos desembolsos } \\
\text { (Condicionantes) }\end{array}$ & $\begin{array}{l}\text { Área de } \\
\text { Resultado }\end{array}$ & Estratégia \\
\hline \multirow{5}{*}{$\begin{array}{l}\text { ALIVIO DA POBRE- } \\
\text { ZA RURAL }\end{array}$} & $\begin{array}{l}\text { Projeto de Comba- } \\
\text { te à Pobreza Rural }\end{array}$ & $\begin{array}{l}\text { Número de famílias be- } \\
\text { neficiadas pelo PCPR } \\
\text { (iniciando em 2010) }\end{array}$ & $\begin{array}{l}\text { Desenvolvimento } \\
\text { do Norte de Mi- } \\
\text { nas, Jequitinho- } \\
\text { nha, Mucuri e Rio } \\
\text { Doce }\end{array}$ & $\begin{array}{l}\text { Desenvolver a produção local, com } \\
\text { ênfase na formação profissional, } \\
\text { na alfabetização, no empreende- } \\
\text { dorismo e no acesso a mercados }\end{array}$ \\
\hline & $\begin{array}{l}\text { Projeto de Comba- } \\
\text { te à Pobreza Rural }\end{array}$ & $\begin{array}{l}\text { Monitoramento inten- } \\
\text { sivo do PCPR }\end{array}$ & - & - \\
\hline & - & $\begin{array}{l}\text { Melhoria nos dados } \\
\text { de pobreza de Minas } \\
\text { Gerais }\end{array}$ & $\begin{array}{l}\text { Qualidade e Ino- } \\
\text { vação em Gestão } \\
\text { Pública }\end{array}$ & $\begin{array}{l}\text { Ampliar, agilizar e dinamizar o } \\
\text { sistema de estatísticas de MG, para } \\
\text { que se tenham informações tem- } \\
\text { pestivas e de qualidade, capazes } \\
\text { de fornecer subsídios para tomada } \\
\text { de decisão* }\end{array}$ \\
\hline & $\begin{array}{l}\text { Educação profis- } \\
\text { sionalizante }\end{array}$ & $\begin{array}{l}\text { Número de escolas do } \\
\text { Ensino Médio no Gran- } \\
\text { de Norte que oferecem } \\
\text { cursos de formação pro- } \\
\text { fissional de montagem e } \\
\text { manutenção de compu- } \\
\text { tadores }\end{array}$ & $\begin{array}{l}\text { Protagonismo Ju- } \\
\text { venil }\end{array}$ & $\begin{array}{l}\text { Ampliar a oferta e melhorar a } \\
\text { qualidade do Ensino Profissiona- } \\
\text { lizante* }^{*}\end{array}$ \\
\hline & - & $\begin{array}{l}\text { Proporção de nascidos } \\
\text { vivos de mães com } 7 \\
\text { ou mais consultas de } \\
\text { pré-natal no Grande } \\
\text { Norte }\end{array}$ & Vida Saudável & $\begin{array}{l}\text { Reduzir a mortalidade materno- } \\
\text { infantil. }\end{array}$ \\
\hline
\end{tabular}

* Não é apresentado como um dos objetivos estratégicos, mas como um meio para atingi-los.

Fonte: Minas Gerais, 2007; World Bank, 2008b, elaboração própria.

Dentre todos os projetos estratégicos apoiados pela parceria, apenas três não constavam de forma explicita no PMDI, as parcerias público-privadas e as ações de saúde e educação indígena. Vale ressaltar, entretanto, que as PPPs constavam no PMDI 2003-2020, mas foram retiradas na revisão do ano de 2007.

Dessa maneira, pode-se afirmar que a Segunda Parceria representou a consolidação da relação entre os dois atores em termos econômicos e de cooperação técnica. Fica evidente que o Banco Mundial e o governo do estado de Minas Gerais possuíam objetivos e estratégias de desenvolvimento compatíveis. O que nos remete à questão da seletividade, apresentada na seção anterior. 


\section{A Terceira Parceria para o Desenvolvimento de Minas Gerais}

A Terceira Parceria para o Desenvolvimento de Minas Gerais é o último empréstimo do período analisado. Firmada no final de 2012, teve como objetivo “auxiliar o Governo de Minas Gerais a aprofundar o seu modelo de gestão inovador, reforçar a sua gestão orçamentária e sua gestão de políticas setoriais nas áreas de inclusão social, gestão ambiental e governança metropolitana” (WORLD BANK, 2012b, p. 34).

O empréstimo buscou apoiar quatro áreas de resultados, sendo elas: o fortalecimento da gestão pública e orçamentária; a promoção da inclusão social; a melhoria da sustentabilidade ambiental; e o desenvolvimento de uma estrutura de governança metropolitana. Dentro de cada área, foram definidos um ou mais objetivos de desenvolvimento. E, assim como nos empréstimos anteriores, as áreas apoiadas são compatíveis com os objetivos estratégicos traçados pelo governo. Segundo o BIRD, “[a] operação baseia-se na estratégia e nas prioridades do Governo, como refletido em seu plano multianual de desenvolvimento integrado [sic] (PMDI), no seu plano plurianual (PPA) e em outros documentos de setores específicos” (WORLD BANK, 2012b, p. 38).

Para financiar tais áreas, a operação disponibilizou para Minas Gerais US\$ 450 milhões por meio de um DPL. A nova parceria possuía um desembolso único no valor total da operação, o que pode demonstrar uma maior confiança do BIRD no estado. Isto porque, nesse tipo de empréstimo, o poder de coerção do credor, caso o programa de reformas não seja devidamente implementado, é menor, uma vez que todo o recurso já está em poder do mutuário.

A realização de um desembolso único não significou, porém, a inexistência de condicionantes ao empréstimo. O banco e o Estado acordaram dez ações que deveriam ser cumpridas pelo Estado previamente à efetivação do empréstimo, que, no geral, eram constituídas pela criação de assessorias, comitês, decretos, resoluções, entre outros, considerados vitais para o sucesso da parceria (WORLD BANK, 2012b). O Quadro 3, apresentado abaixo, ilustra a aderência entre as ações prévias (condicionantes ex ante) de cada área apoiada pelo empréstimo e as estratégias delineadas no PMDI 2011-2030. 


\section{Quadro 3. Comparativo entre a Terceira Parceria para o Desenvolvimento de Minas Gerais (2012) e o Plano Mineiro de Desenvolvimento Integrado 2011-2030}

\begin{tabular}{|c|c|c|c|}
\hline \multicolumn{2}{|c|}{$\begin{array}{c}\text { Terceira Parceria para o Desenvolvimento } \\
\text { de Minas Gerais (2012) }\end{array}$} & \multicolumn{2}{|c|}{$\begin{array}{l}\text { Plano Mineiro de Desenvolvimento Integrado } \\
\qquad(2011-2030)\end{array}$} \\
\hline Objetivos & $\begin{array}{l}\text { Ações Prévias ao Desembolso do } \\
\text { Empréstimo (Condicionantes) }\end{array}$ & Área de Resultado & Estratégias Prioritárias \\
\hline \multicolumn{4}{|c|}{ Área 1. Fortalecimento do Setor Público e Gestão Orçamentária } \\
\hline $\begin{array}{l}\text { 1.1 Aumentar a ro- } \\
\text { bustez e susten- } \\
\text { tabilidade do } \\
\text { Modelo de Ges- } \\
\text { tão Baseada em } \\
\text { Resultados }\end{array}$ & $\begin{array}{l}\text { 1. O Mutuário: (i) estabeleceu } 22 \text { As- } \\
\text { sessorias de Gestão Estratégica e } \\
\text { Inovação com vistas a descentralizar } \\
\text { as funções de gestão baseada em } \\
\text { resultados do Mutuário [...] }\end{array}$ & \multirow{3}{*}{$\begin{array}{l}\text { Rede de Governo } \\
\text { Integrado, Eficiente } \\
\text { e Eficaz }\end{array}$} & $\begin{array}{l}\text { Acentuar a orientação da estratégia } \\
\text { governamental para as entregas e } \\
\text { os resultados para a sociedade. } \\
\text { Cultivar um ambiente propício } \\
\text { e desenvolver instrumentos que } \\
\text { estimulem a geração, a adoção e } \\
\text { a disseminação de inovações na } \\
\text { gestão pública. }\end{array}$ \\
\hline \multirow[b]{2}{*}{$\begin{array}{l}\text { 1.2 Aumentar a pre- } \\
\text { visibilidade e o } \\
\text { controle da exe- } \\
\text { cução orçamen- } \\
\text { tária }\end{array}$} & $\begin{array}{l}\text { 2. O Mutuário adotou o Módulo de } \\
\text { Programação Orçamentária do Sis- } \\
\text { tema Integrado de Administração } \\
\text { Financeira - SIAFI/MG [...] }\end{array}$ & & \multirow[b]{2}{*}{$\begin{array}{l}\text { Aumentar a qualidade e a produ- } \\
\text { tividade do gasto setorial, com } \\
\text { ênfase na melhoria da composição } \\
\text { estratégica do gasto e no aumento } \\
\text { da aderência do orçamento à es- } \\
\text { tratégia de desenvolvimento do } \\
\text { Estado }\end{array}$} \\
\hline & $\begin{array}{l}\text { 3. O Mutuário adotou medidas para } \\
\text { avaliar projetos de valor superior a } \\
\text { R\$ } 5 \text { milhões e cofinanciados através } \\
\text { de Transferências Voluntárias pelo } \\
\text { Garantidor, efetuadas no território } \\
\text { do Mutuário antes de apresentar tais } \\
\text { projetos à Câmara de Coordenação } \\
\text { Geral, Planejamento, Gestão e Finan- } \\
\text { ças para aprovação [...] }\end{array}$ & & \\
\hline $\begin{array}{l}\text { 1.3 Aumentar a par- } \\
\text { ticipação cidadã na } \\
\text { definição de priori- } \\
\text { dades regionais }\end{array}$ & $\begin{array}{l}\text { 4. O Mutuário: (i) criou dois comi- } \\
\text { tês regionais no seu território, um } \\
\text { para a região Norte de Minas e um } \\
\text { para a região do Rio Doce, para } \\
\text { implementar em caráter piloto um } \\
\text { processo participativo para aumentar } \\
\text { a participação da sociedade. }\end{array}$ & $\begin{array}{l}\text { Rede de Governo } \\
\text { Integrado, Eficiente } \\
\text { e Eficaz }\end{array}$ & $\begin{array}{l}\text { Ampliar os espaços públicos ins- } \\
\text { titucionalizados voltados para a } \\
\text { construção participativa de políti- } \\
\text { cas públicas estaduais }\end{array}$ \\
\hline \multicolumn{4}{|c|}{ Área 2. Promoção da Inclusão Social } \\
\hline \multirow{2}{*}{$\begin{array}{l}\text { 2.1 Reduzir a po- } \\
\text { breza nas áreas } \\
\text { mais desfavo- } \\
\text { recidas, a fim } \\
\text { de reduzir a } \\
\text { exclusão e as } \\
\text { desigualdades } \\
\text { regionais }\end{array}$} & $\begin{array}{l}\text { 5. O Mutuário, através da SEDESE: } \\
\text { (i) estabeleceu o Piso Mineiro [da } \\
\text { Assistência Social] [...] }\end{array}$ & \multirow{2}{*}{$\begin{array}{l}\text { Rede de Desenvol- } \\
\text { vimento Social e } \\
\text { Proteção }\end{array}$} & $\begin{array}{l}\text { Universalizar o Piso Mineiro de } \\
\text { Assistência Social, por meio de } \\
\text { compartilhamento financeiro da } \\
\text { infraestrutura da rede de assistên- } \\
\text { cia social, em complementaridade } \\
\text { aos recursos federais e municipais }\end{array}$ \\
\hline & $\begin{array}{l}\text { 6. O Mutuário alterou a regulamentação } \\
\text { sobre o Programa Travessia de forma } \\
\text { a incluir, entre outras disposições, } \\
\text { uma que prevê a realização pelo } \\
\text { Mutuário de um diagnóstico sobre } \\
\text { educação, saúde e qualidade de vida } \\
\text { nos municípios selecionados [...] }\end{array}$ & & $\begin{array}{l}\text { Identificar a população em extre- } \\
\text { ma pobreza e direcionar ações de } \\
\text { desenvolvimento social para supe- } \\
\text { ração do estado de pobreza }\end{array}$ \\
\hline
\end{tabular}


(continuação)

\begin{tabular}{|c|c|c|c|}
\hline \multicolumn{2}{|c|}{$\begin{array}{c}\text { Terceira Parceria para o Desenvolvimento } \\
\text { de Minas Gerais (2012) }\end{array}$} & \multicolumn{2}{|c|}{$\begin{array}{l}\text { Plano Mineiro de Desenvolvimento Integrado } \\
\qquad(2011-2030)\end{array}$} \\
\hline Objetivos & $\begin{array}{l}\text { Ações Prévias ao Desembolso do } \\
\text { Empréstimo (Condicionantes) }\end{array}$ & Área de Resultado & Estratégias Prioritárias \\
\hline \multicolumn{4}{|c|}{ Área 2. Promoção da Inclusão Social } \\
\hline $\begin{array}{l}\text { 2.2 Fortalecimento } \\
\text { da gestão da edu- } \\
\text { cação }\end{array}$ & $\begin{array}{l}\text { 7. O Mutuário adotou e está imple- } \\
\text { mentando um processo de seleção } \\
\text { baseado no mérito para superinten- } \\
\text { dentes escolares regionais e diretores } \\
\text { escolares do seu território [...] }\end{array}$ & $\begin{array}{l}\text { Rede de Educação } \\
\text { e Desenvolvimento } \\
\text { Humano }\end{array}$ & $\begin{array}{l}\text { Desenvolver a capacidade gerencial } \\
\text { dos diretores das escolas públicas } \\
\text { por meio da seleção baseada em } \\
\text { critérios de mérito e liderança, da } \\
\text { avaliação e premiação por resulta- } \\
\text { dos, da interligação dos profissio- } \\
\text { nais em rede e da certificação ocu- } \\
\text { pacional dos gestores educacionais }\end{array}$ \\
\hline \multicolumn{4}{|c|}{ Área 3. Melhoria da Sustentabilidade Ambiental } \\
\hline \multirow{2}{*}{$\begin{array}{l}\text { 3.1 Aumentar a ca- } \\
\text { pacidade do } \\
\text { Estado de fazer } \\
\text { frente aos desa- } \\
\text { fios ambientais }\end{array}$} & $\begin{array}{l}\text { 8. O Mutuário estabeleceu, dentro de } \\
\text { sua Secretaria de Meio Ambiente e } \\
\text { Desenvolvimento Sustentável, uma } \\
\text { Subsecretaria de Gestão e Regula- } \\
\text { rização Ambiental e uma Subse- } \\
\text { cretaria de Controle e Fiscalização } \\
\text { Ambiental [...] }\end{array}$ & $\begin{array}{l}\text { Rede de Desenvol- } \\
\text { vimento Econômico } \\
\text { Sustentável }\end{array}$ & $\begin{array}{l}\text { Conferir maior agilidade e efetivi- } \\
\text { dade ao licenciamento ambiental* }\end{array}$ \\
\hline & $\begin{array}{l}\text { 9. O Mutuário adotou medidas para in- } \\
\text { centivar o plantio de florestas em seu } \\
\text { território com o objetivo de fornecer } \\
\text { matéria-prima para as indústrias nele } \\
\text { localizadas }[\ldots]\end{array}$ & - & - \\
\hline \multicolumn{4}{|c|}{ Área 4. Desenvolvimento de uma estrutura de governança metropolitana } \\
\hline $\begin{array}{l}4.1 \text { Fortalecer a Go- } \\
\text { vernança Me- } \\
\text { tropolitana para } \\
\text { permitir a coor- } \\
\text { denação de polí- } \\
\text { ticas públicas es- } \\
\text { taduais e muni- } \\
\text { cipais na Região } \\
\text { Metropolitana de } \\
\text { Belo Horizonte } \\
\text { (RMBH) }\end{array}$ & $\begin{array}{l}\text { 10. O Mutuário, através do Conse- } \\
\text { lho Deliberativo de Desenvolvi- } \\
\text { mento da Região Metropolitana de } \\
\text { Belo Horizonte, adotou um plano } \\
\text { diretor de desenvolvimento regional } \\
\text { integrado para a região metropolita- } \\
\text { na de Belo Horizonte [...]. }\end{array}$ & Rede de Cidades & $\begin{array}{l}\text { Induzir e apoiar a formulação } \\
\text { de planos regionais estratégicos } \\
\text { para as regiões do estado com a } \\
\text { participação da população local, } \\
\text { bem como estimular e assessorar } \\
\text { a formação de consórcios públicos } \\
\text { intermunicipais, nos casos per- } \\
\text { tinentes, e fortalecer os arranjos } \\
\text { metropolitanos }\end{array}$ \\
\hline
\end{tabular}

Fonte: MINAS GERAIS, 2011; WORLD BANK, 2012b, elaboração própria. 


\section{Conclusões}

A hipótese que se buscou verificar no presente trabalho era a de que o Banco Mundial, mediante o atrelamento da liberação de recursos ao cumprimento de certas condicionantes definidas em contrato, conseguiria influenciar a definição da estratégia de desenvolvimento do Estado e, consequentemente, o processo de construção de políticas públicas.

Constatamos, entretanto, que houve um forte alinhamento entre as condicionantes estipuladas e os objetivos e estratégias previamente definidos pelo Estado. Isso foi verificado pelo fato de que grande parte das ações financiadas e suas condicionantes, em geral, constavam no PMDI como uma estratégia ou um objetivo estratégico de desenvolvimento.

O alto nível de alinhamento demonstrou que a hipótese inicial desse trabalho não era válida, já que, se o banco buscasse influenciar significativamente a estratégia de desenvolvimento do Estado, veríamos condicionantes que não convergiriam com os objetivos e estratégias apresentados no PMDI. Diante disso, concluímos que o Banco Mundial, devido à própria evolução de sua estratégia de atuação, quando se afasta das políticas prescritivas do Consenso de Washington e se volta para o apoio de programas elaborados internamente pelos países financiados, levando em conta os critérios de seletividade e ownership, não se utiliza das condicionantes para interferir na estratégia de desenvolvimento do estado de Minas Gerais. O critério de seletividade é essencial para entender essa situação. Como o banco passa a utilizá-lo para definir quais Estados apoiar, e decide por firmar uma parceria com Minas Gerais, isto significa que ele considera a estratégia de desenvolvimento do estado, traduzida em seu programa de reformas, sólida.

Isso não significa, porém, que o Banco Mundial não tenha influenciado a estratégia de desenvolvimento de Minas Gerais, apenas que as condicionantes não foram o mecanismo utilizado para fazê-lo. A aquiescência de diversos países às orientações do Consenso, o Brasil incluso, possibilitou a incorporação (ao menos em parte) das novas diretrizes para o desenvolvimento nos moldes propostos pelas agências interestatais internacionais. É possível que a seletividade tenha criado um incentivo para que o governo do estado de Minas Gerais criasse um plano de desenvolvimento com estratégias compatíveis àquelas favorecidas pelo Banco Mundial, visando ter acesso aos empréstimos junto ao banco. Autores como Koeberle (2003) e Morrow (2005) apontam que a seletividade pode incentivar potenciais mutuários a fingir ter ownership sobre um conjunto de políticas indicadas pelo banco. Tal hipótese deve ser testada em um estudo futuro. 


\section{Referências}

ANCOCHEA, Diego Sánchez. El modelo económico en América Latina desde los años noventa hasta la Gran Crisis: ¿Um modelo razonable o un fracaso liberal? Revista CIDOB d'Afers Internacionals, n. 85/86, Los Retos de América Latina en un Mundo en Cambio, maio 2009, p. 133-155. Disponível em: < http://www.jstor.org/ stable/40586390 > . Acesso em: 07 de mar. 2017.

BÉJAR, Ramón Casilda. El 'consenso de Washington'. Política Exterior, v. 16, n. 86, mar.-abr. 2002, p. 109-117, 119-124, 127-128. Disponível em: < http://www.jstor. org/stable/20645248 > . Acesso em: 07 mar. 2017.

BRESSER-PEREIRA, Luiz Carlos. A teoria do desenvolvimento econômico e a crise de identidade do Banco Mundial. Revista de Economia Política, São Paulo, v. 15, n. 1, jan.-mar. 1995. p. 5-40.

CHIARI, Mirna S. As atuais funções do Banco Mundial no contexto dos ajustes estruturais no Brasil. Belo Horizonte. Dissertação (mestrado). Escola de Governo Professor Paulo Neves de Carvalho da Fundação João Pinheiro. 2000.

CLEMENS, Michael A. e KREMER, Michael. The New Role for the World Bank. The Journal of Economic Perspectives, v. 30, n. 1, inverno 2016, p. 53 - 76. Disponível em: < http://www.jstor.org/stable/43710010 > . Acesso em: 03 mar. 2017.

CYPHER, James M. The Slow Death of the Washington Consensus on Latin America. Latin American Perspectives, Issue 103, vol. 25. N 6. Nov. 1998. p. 47-51.

DRAZEN, Allan. Conditionality and ownership in IMF lending: A political economy approach. In: RANIS, Gustav (ed.); VREELAND, James R. (ed.); KOSACK, Stephen (ed.). Globalization and the Nation State: The impact of the IMF and the World Bank. Nova York: Routledge. 2006. Cap. 3, p. 51-81.

DREHER, Axel. A Public Choice Perspective of IMF and World Bank Lending and Conditionality. Public Choice, Nova York, v. 119, n. 3/4, jun. 2004. p. 445-464.

ENNS, Charis. Knowledges in competition: Knowledge discourse at the World Bank during the Knowledge for Development era. Global Social Policy, v. 15, n. ${ }^{\circ}$ 1, 2015, p. 61-80.

FINE, Ben; LAPAVITSAS, Costas; PINCUS, Jonathan (Eds.). Development Policy in the Twenty-fist Century - Beyond the post-Wahington Consensus. London, Routledge. 2001.

GATTI, Marcos. Sobre o Conceito de Políticas Públicas e suas Consequências para a Orientação Profissional. São Paulo. Tese (doutorado). Instituto de Psicologia da Universidade de São Paulo. 2011.

KATZ, Claudio. Dualities of Latin America. Latin American Perspectives, Issue 203, vol. 42. $\mathrm{N}^{\circ}$ 4. Nov. 2015. p. 10-42.

KOEBERLE, Stefan G. Should Policy-Based Lending Still Involve Conditionality? The World Bank Research Observer, Oxford, v. 18, n. 2, outono. 2003. p. 249-273. 
LICHTENSZTEJN, Samuel. Fondo Monetario Internacional y Banco Mundial: instrumentos del poder financiero. Xalapa, México: Universidad Veracruzana. 2010.

MARANGOS, John. The Evolution of the Anti-Washington Consensus Debate: From 'Post-Washington Consensus' to 'After the Washington Consensus'. Competition \& Change, vol. 12, No 3. Sep. 2008. p. 227-244.

MINAS GERAIS. Secretaria de Estado de Planejamento e Gestão. Plano Mineiro de Desenvolvimento Integrado (PMDI) 2011-2030. Belo Horizonte, 2011. 151 p.

MINAS GERAIS. Secretaria de Estado de Planejamento e Gestão. Plano Mineiro de Desenvolvimento Integrado (PMDI) 2007-2023. Belo Horizonte, 2007. 49 p.

MINAS GERAIS. Secretaria de Estado de Planejamento e Gestão. Plano Mineiro de Desenvolvimento Integrado (PMDI) 2003-2020. Belo Horizonte, 2003. 125 p.

MONTIEL, Héctor Cuadra. Incompleteness of Post-Washington Consensus: A Critique of Macro-economic and Institutional Reforms. International Studies, Vol. 44, $\mathrm{n}^{\circ} 2$. 2007. p. 103-122.

MORROW, Daniel. Adjusting conditionality: prescriptions for policy-based lending. In: KOEBERLE, Stefan (ed.); BEDOYA, Harold (ed.); SILARKY, Peter (ed.); VERHEYEN, Gero (ed.), Conditionality revisited: concepts, experiences, and lessons, Washington: World Bank, 2005. Cap. 21, p. 197-223.

PALONI, Alberto; ZANARDI, Maurizio. Development Policy Lending, conditionality and ownership: a political economy model. CREDIT Research Paper, Nottingham, n. 10, nov. 2005.

RANIS, Gustav. Ownership, Dutch Disease and the World Bank. In: RANIS, Gustav (ed.); VREELAND, James Raymond (ed.); KOSACK, Stephen (ed.). Globalization and the Nation State: The impact of the IMF and the World Bank. Nova York: Routledge. 2006. Cap. 16, p. 419-426.

RAVALLION, Martin. The World Bank: Why It Is Still Needed and Why It Still Disappoints. The Journal of Economic Perspectives, v. 30, n. 1, inverno 2016. p. 77-94. Disponível em: http://www.jstor.org/stable/43710011. Acesso em: 03 mar. 2017.

RODRIK, Dani. Goodbye Washington Consensus, hello Washington confusion? A review of the World Bank's Economic Growth in the 1990s: Learning from a Decade of Reform. Journal of Economic Literature, Pittsburgh, v. 44, n. 4, dez. 2006. p. 973-987. RUGER, Jennifer Prah. The Changing Role of the WORLD BANK in Global Health. American Journal of Public Health, Washington, v. 95, n. 1, jan. 2005. p. 60-70.

SACHS, Jeffrey D. Conditionality, Debt Relief, and the Developing Country Debt Crisis. In: SACHS, Jeffrey D. (ed), Developing Country Debt and Economic Performance: The International Financial System. Chicago: The University of Chicago Press. 1989. Cap. 14, p. 275-284. 
SANTISO, Carlos. Good Governance and Aid Effectiveness: The World Bank and Conditionality. The Georgetown Public Policy Review, Washington, v. 7, n. 1, outono, 2001. p. 1-22.

SANTOS JUNIOR, Raimundo B. dos. As políticas sociais do Banco Mundial para os países em desenvolvimento. Campinas. Tese (doutorado). Instituto de Filosofia e Ciências Humanas, Universidade Estadual de Campinas, Campinas. 2010.

STIGLITZ, Joseph. Is there a Post-Washington Consensus Consensus?. In: NARCÍS, Serra (ed.); STIGLITZ, Joseph (ed.), The Washington Consensus Reconsidered. Oxford: Oxford University Press. 2008. Cap. 4, p. 41-56.

STIGLITZ, Joseph. The World Bank at the Millennium. The Economic Journal, Oxford, n. 109, nov. 1999. p. 577-597.

WILliAMSON, John. The Washington Consensus as Policy Prescription for Development. In: Practitioners of Development, 2004, Washington. Anais... Washington, 2004. Disponível em < https://piie.com/publications/papers/williamson0204.pdf > . Acesso em: 05 mar. 2017.

WORLD BANK. International Bank for Reconstruction and Development. World Bank. 2014. Disponível em: < http://go.worldbank.org/65RBCJ2IW0 > . Acesso em: 06 jun. 2014. WORLD BANK. Brasil - Terceiro Programa de Parceria para o desenvolvimento do Estado de Minas Gerais, Washington. 2012.

WORLD BANK. The importance of stakeholder ownership for capacity development results, Washington, 2011.

WORLD BANK. Brazil - Additional Financing for the Second Minas Gerais Partnership (SWAP) Project, Washington. 2010.

WORLD BANK. Brazil - Second Minas Gerais Partnership (SWAP) Project, Washington. 2008. WORLD BANK. Brazil - Minas Gerais Partnership for Development Project, Washington. 2006. WORLD BANK. Economic Growth in the 1990s: Learning from a Decade of Reform, Washington, 2005a.

WORLD BANK. Review of World Bank conditionality: legal aspects of conditionality in policy-based lending, Washington, 2005b.

WORLD BANK. World Bank history. World Bank. (s.d.). Disponível em: < http://go.world bank.org/W3SF2UKO71 > . Acesso em: 06 jun. 2014. 